\title{
Stress sensitivity is increased in transgenic rats with low brain angiotensinogen
}

\author{
Helge Müller ${ }^{1}$, Juliane Kröger ${ }^{1}$, Olaf Jöhren ${ }^{1}$, Silke Szymczak ${ }^{2}$, Michael Bader ${ }^{3}$, Peter Dominiak ${ }^{1}$ \\ and Walter Raasch ${ }^{\mathbf{1}}$ \\ ${ }^{1}$ Institute of Experimental and Clinical Pharmacology and Toxicology and ${ }^{2}$ Institute of Medical Biometry and Statistics, University of Lübeck, Ratzeburger \\ Allee 160, 23538 Lübeck, Germany \\ ${ }^{3}$ Max-Delbrück-Center for Molecular Medicine (MDC), Berlin-Buch, 13125 Berlin, Germany \\ (Correspondence should be addressed to W Raasch; Email: raasch@medinf.mu-luebeck.de)
}

\begin{abstract}
$\mathrm{AT}_{1}$ blockers attenuate hypothalamo-pituitary-adrenal (HPA) axis reactivity in hypertension independently of their potency to lower blood pressure. A reduced pituitary sensitivity to $\mathrm{CRH}$ and a downregulation of hypothalamic CRH expression have been suggested to influence HPA axis activity during chronic $\mathrm{AT}_{1}$ blockade. This study was aimed at confirming the role of central angiotensin II in regulating HPA reactivity by using the transgenic rat TGR(ASrAOGEN), a model featuring low levels of brain angiotensinogen. Different stress tests were performed to determine HPA reactivity in TGR(ASrAOGEN) and appropriate controls. In TGR(ASrAOGEN), blood pressure was diminished compared to controls. The corticosterone response to a $\mathrm{CRH}$ or ACTH challenge and a forced swim test was more distinct in TGR(ASrAOGEN) than it was in controls and occurred independently of a concurrent enhancement in ACTH. Using quantitative real-time PCR, we found
\end{abstract}

increased mRNA levels of melanocortin $2(M c 2 r)$ and $\mathrm{AT}_{2}$ receptors (Agtr2) in the adrenals of TGR(ASrAOGEN), whereas mRNA levels of $\mathrm{Crh}$, Pomc, and $\mathrm{AT}_{1}$ receptors (Agtr1) remained unchanged in hypothalami and pituitary glands. Since stress responses were increased rather than attenuated in TGR(ASrAOGEN), we conclude that the reduced HPA reactivity during $\mathrm{AT}_{1}$ blockade could not be mimicked in a specific transgenic rat model featuring a centrally inactivated renin-angiotensin-aldosterone system. The ACTH independency of the enhanced corticosterone release during $\mathrm{CRH}$ test and the enhanced corticosterone response to ACTH rather indicates an adrenal mechanism. The upregulation of adrenal $\mathrm{MC} 2$ and $\mathrm{AT}_{2}$ receptors seems to be involved in the stimulated facilitation of adrenal corticosterone release for effectuating the stimulated stress responses.

Journal of Endocrinology (2010) 204, 85-92

\section{Introduction}

Over the last few years, it has been established that angiotensin II (Ang II) AT receptors (AGTR as listed in the MGI Database) are present in the organs of the hypothalamopituitary-adrenal (HPA) axis (Burson et al. 1994, Gasc et al. 1994, Llorens-Cortes et al. 1994, Jöhren et al. 1995, Jöhren \& Saavedra 1996), that they are regulated during stress (Castren \& Saavedra 1988, Aguilera et al. 1995, Leong et al. 2002), and that Ang II influences HPA axis reactivity by enhancing the synthesis and secretion of CRH, ACTH, and glucocorticoids (Rivier \& Vale 1983, Abou-Samra et al. 1986, Schoenenberg et al. 1987, Sumitomo et al. 1991, Naville et al. 1993, Jezova et al. 1998). This crosstalk between the renin-angiotensinaldosterone system (RAAS) and the HPA axis is functionally relevant for hypertension. In the transgenic rat TGR(mREN2)27 (which develops a fulminant hypertension as a result of the integrated mouse $\mathrm{Ren}-2 \mathrm{~d}$ renin gene into its genome), the urinary excretion of corticosterone is increased during the developmental phase of hypertension, the adrenal response to ACTH is stimulated (Sander et al. 1992), and hypertension can be prevented when HPA reactivity is suppressed by dexamethasone (Djavidani et al. 1995). In spontaneously hypertensive rats (SHR), the Ang II-induced release of $\mathrm{ACTH}$ and corticosterone is stimulated compared to normotensive WKY rats, an observation that has been linked to a higher expression of $\mathrm{AT}_{1 \mathrm{~A}}$ receptors $($ Agtr $1 a)$ in the pituitary gland (Jöhren et al. 2003). From a therapeutic viewpoint, chronic $\mathrm{AT}_{1}$ receptor blockade diminishes HPA reactivity in rats in a blood pressure-independent manner (Seltzer et al. 2004, Raasch et al. 2006). Reductions in HPA reactivity induced by $\mathrm{AT}_{1}$ blockade have been suggested to mediate metabolic benefits, since on the one hand the HPA axis is hyperreactive in diabetes (Chan et al. 2002, 2003, Jöhren et al. 2007) and on the other hand glucose utilization is enhanced after $\mathrm{AT}_{1}$ blockade through a concurrent alteration in HPA reactivity (Uresin et al. 2004, Raasch et al. 2006, Müller et al. 2007). 
Even though a functional impact of the interaction between the RAAS and the HPA axis has been demonstrated for hypertension, whether the reactivity of the HPA axis in response to peripherally applied $\mathrm{AT}_{1}$ blockers or Ang II reflects a central (hypothalamic or pituitary) and/or a peripheral (adrenal) mechanism has not been sufficiently addressed. Both a reduced pituitary sensitivity to $\mathrm{CRH}$ and a downregulation of hypothalamic $\mathrm{CRH}$ expression have been discussed as reducing HPA axis activity during chronic $\mathrm{AT}_{1}$ blockade or angiotensin-converting enzyme inhibition (Raasch et al. 2006). We aimed to answer this question in the present study by using the transgenic rats with low brain angiotensinogen (TGR (ASrAOGEN)) (Schinke et al. 1999). In TGR(ASrAOGEN), angiotensinogen protein concentration was reduced to $10 \%$ in medulla, pons, hypothalamus, thalamus, and cerebellum compared to controls, while angiotensinogen plasma concentrations and plasma renin activity were similar. This transgenic rat lacking in brain Ang II induced a $6-8 \mathrm{mmHg}$ decrease in blood pressure (Schinke et al. 1999). The hypotension is comparable to the efficacy of $\mathrm{AT}_{1}$ blockers at antagonizing an Ang II-induced increase in blood pressure when administered i.c.v. (Oliveira et al. 1996, Camara \& Osborn 1998). Since the RAAS activity has been demonstrated to be impaired in the brain specifically, these transgenic rats may corroborate the functional significance of local Ang II production in the brain for centrally regulating the reactivity of the HPA axis.

\section{Material and Methods}

\section{Animals}

Eight-week-old transgenic rats deficient in brain angiotensinogen TGR(ASrAOGEN) were obtained from the Max-Delbrück-Center for Molecular Medicine (MDC), Berlin-Buch, Germany. Age-matched Hannover SpragueDawley rats (also from MDC) served as controls. The study was conducted according to the NIH guidelines for the care and use of laboratory animals, and was authorized by the local regulatory authority (Ministerium für Landwirtschaft, Umwelt und ländliche Räume des Bundeslandes SchleswigHolstein). The animals were kept at room temperature with a $12 \mathrm{~h} / 12 \mathrm{~h}$ darkness (1400-0200 h)/light (0200-1400 h) cycle. They received a standard diet and water ad libitum.

\section{Study protocol}

Protocol 1 At the age of 17 weeks, chronic polyethylene catheters were inserted during pentobarbitone anesthesia into the right femoral vein and artery. Catheters were tunneled under the back skin, exteriorized in the region of the cervical vertebra, and fixed at the skin. Thereafter, rats were housed individually in cages (height $X$ width $\times$ length: $20 \times 22 \times 25 \mathrm{~cm}$ ) until the end of the study. Blood pressure was monitored via arterial catheters 2 days after catheterization at between 0900 and $1000 \mathrm{~h}$ in conscious rats. Values were recorded for $5 \mathrm{~min}$. Blood pressure and heart rate were averaged over two time periods ( $30 \mathrm{~s}$ each) when conditions were stable. One day later, CRH tests were performed (Raasch et al. 2006, Müller et al. 2007). During the CRH tests, rats had free access to water and food. Three hours before starting the tests, arterial catheters were extended by $\sim 4 \mathrm{~cm}$ to avoid stress reactions during blood withdrawal. CRH $(10 \mu \mathrm{g} / \mathrm{kg}$, i.v. $)$ was injected $4 \mathrm{~h}$ before the light cycle. During the $\mathrm{CRH}$ tests, the lights at working benches were kept as dim as possible to maintain the darkness period. Before $\mathrm{CRH}$ injections and at regular intervals over a 4 -h time period, $50 \mu \mathrm{l}$ blood was withdrawn for analysis of corticosterone and ACTH. To avoid hemorrhage-induced alterations, platelets and erythrocytes were reconstituted and returned to each animal.

Protocol 2 A second set of age-matched rats undertook the forced swim test (FST). Before stress testing, blood samples were taken from a tail nick in order to distinguish the baseline conditions of the stress hormones. Thirty minutes after swimming $(10 \mathrm{~min}$ ) in a basin (diameter $35 \mathrm{~cm}$, water depth $20 \mathrm{~cm}$, and water temperature $15^{\circ} \mathrm{C}$ ), tail blood was taken again for the determination of corticosterone and ACTH.

Protocol 3 In a third set of animals (17 weeks), an ACTH test was performed 3 days after catheter insertions (see protocol 1). Before ACTH injections $(2 \mu \mathrm{g} / \mathrm{kg}$, i.v.) and at regular intervals within a 4 -h time period, $30 \mu$ blood was withdrawn. During ACTH tests, the lights at the working benches were kept as dim as possible.

Protocol 4 Organs and blood for the biochemical/molecular analysis were obtained from age-matched animals that were not included in any functional tests. Rats of this group were housed and handled similar to the rats of the other protocols. These rats had not been catheterized to avoid any surgery stress. Thus, surgery-induced alterations in baseline ACTH and corticosterone could be eliminated and MC2 receptor, $\mathrm{CRH}$ and AT receptors reflect native expression in organs of the HPA axis in these rats.

\section{Biochemical analysis}

Plasma concentrations of ACTH, corticosterone, and aldosterone were determined by RIAs using commercial kits (all from MP Biomedicals, Eschwege, Germany). Assays were performed as recommended by the manufacturers (Raasch et al. 2006, Müller et al. 2007). Norepinephrine and epinephrine were measured in plasma that was obtained one day after catheter insertion by HPLC and electrochemically as previously described (Raasch et al. 2004a, 2005).

\section{$R N A$ isolation and $c D N A$ synthesis}

Hypothalami were dissected according to Paxinos \& Watson (1998). The brains were adapted to $-10{ }^{\circ} \mathrm{C}$, and coronal cuts were made $0.26 \mathrm{~mm}$ (at the optic chiasm) and $4.8 \mathrm{~mm}$ posterior to the bregma. To cut apart the hypothalamus, the 
slice was turned on its posterior surface and cut sagitally $2.6 \mathrm{~mm}$ lateral to the midline directly before the amygdala and horizontally $7.4 \mathrm{~mm}$ under the cortical surface. The neurointermediate lobes were not removed before preparation of pituitary RNA. Hypothalami and pituitary and total adrenal glands were extracted on the ABI PRISM 6100 Nucleic Acid PrepStation (Applied Biosystems) according to the manufacture's instructions (Jöhren et al. 2003). Total RNA was synthesized using oligo-(dT) 15 primer and AMV Reverse Transcriptase (Invitrogen). Contamination with genomic DNA was avoided by thorough treatment with DNase I. cDNA was stored at $-20^{\circ} \mathrm{C}$ until PCR.

\section{$q P C R$}

mRNA steady-state levels of $A T_{1 A}$ (Agtr1a), $A T_{1 B}$ (Agtr1b), $A T_{2}$ (Agtr2), and ACTH receptors (melanocortin 2 receptors $=$ MC2 receptor; $M c 2 r$ ), as well as of proopiomelanocortin (Pomc) and $\mathrm{Crh}$, were quantified in organs of the HPA axis. Quantitative measurements of mRNA were performed by qPCR with the cycle threshold method using SYBR green I as a fluorescent dye on the GeneAmp 7000 sequence detection system (Perkin-Elmer Applied Biosystems, Weiterstadt, Germany), and cDNA-specific primers. Primers for $\mathrm{AT}_{1 \mathrm{~A}}, \mathrm{AT}_{1 \mathrm{~B}}, \mathrm{AT}_{2}$ receptors, $\mathrm{MC} 2$ receptor, POMC and $\mathrm{CRH}$ have been published elsewhere (Raasch et al. 2004b, 2006, Müller et al. 2007). All primers were obtained from Invitrogen. Product specificity was confirmed by dissociation curve analysis and agarose gel electrophoresis. No template controls served as negative controls (Jöhren et al. 2001). Expression values were normalized to total RNA content (Bustin 2002).

\section{Statistical analysis}

Data shown are expressed as means \pm s.E.M. To quantify the total effect over the observation time in response to $\mathrm{CRH}$ regarding changes in plasma concentrations of corticosterone and ACTH, the area under the curves (AUC) was calculated for each individual animal on the basis of their delta values. Correlation analysis was carried out by using Pearson's product moment correlation. For pairwise comparisons, Student's $t$-test was employed, and differences in MC2 receptor mRNA were also analyzed by the median quantitative mutual information score (QMIS; Tsalenko et al. 2006). QMIS is powerful specifically when study groups exhibit different skewness or kurtosis. A two-way ANOVA followed by Bonferroni's post-hoc test for multiple comparisons was performed to examine the effects of two variables. Differences were considered to be statistically significant at $P<0 \cdot 05$.

\section{Results}

Blood pressure was slightly decreased in TGR(ASrAOGEN) compared to controls, whereas heart rate and left ventricular weight were not affected (Table 1). Weight of adrenals was
Table 1 Hemodynamic parameters of TGR(ASrAOGEN) and controls. Means \pm S.E.M. $(n=13)$

\begin{tabular}{|c|c|c|c|}
\hline & Control & TGR(ASrAOGEN) & $\boldsymbol{P}$ \\
\hline $\begin{array}{l}\text { Systolic blood } \\
\text { pressure (mmHg) }\end{array}$ & $124 \pm 2$ & $118 \pm 2$ & $0 \cdot 028$ \\
\hline Heart rate (beats/min) & $370 \pm 10$ & $370 \pm 6$ & 0.969 \\
\hline $\begin{array}{l}\text { Left ventricular } \\
\text { weight }(\mathrm{mg})\end{array}$ & $1067 \pm 31$ & $1034 \pm 25$ & $0 \cdot 429$ \\
\hline
\end{tabular}

similar between the TGR(ASrAOGEN) and the controls $(31 \cdot 9 \pm 2 \cdot 1$ vs $27 \cdot 1 \pm 1 \cdot 1 \mathrm{mg} ; P=0 \cdot 1011)$. Baseline levels of $\mathrm{ACTH}$, corticosterone, and aldosterone did not differ between the two rat strains (Table 2). Moreover, controls and TGR(ASrAOGEN) featured similar plasma levels of norepinephrine and epinephrine (Table 2). Both norepinephrine and epinephrine exceeded the normal range, which might be due to the withdrawal modality.

In response to $\mathrm{CRH}$ stimulation, serum levels of $\mathrm{ACTH}$ and corticosterone sharply increased and returned to baseline levels within $4 \mathrm{~h}$. The plasma profiles of ACTH after CRH stimulation did not differ between both rat strains (Fig. 1A). Despite similar ACTH profiles, the CRH-induced corticosterone response was enlarged in TGR(ASrAOGEN). The maximal concentration $\left(C_{\max } ; 362 \pm 17\right.$ vs $437 \pm 21 \mathrm{ng} / \mathrm{ml}$; $P=0.0158)$ was increased, but $t_{\max }(70 \pm 8$ vs $60 \pm 7 \mathrm{~min}$; $P=0.3589)$ remained unchanged in TGR(ASrAOGEN) compared with the controls (Fig. 1B). The observation that the corticosterone response to $\mathrm{CRH}$ was enlarged in TGR(ASrAOGEN) independently of a concurrent ACTH increase was pointed out by plotting individual AUCs of concentration-time curves of $\mathrm{ACTH}\left(=\mathrm{AUC}_{\mathrm{ACTH}}\right)$ and corticosterone $\left(=\mathrm{AUC}_{\text {corticosterone }}\right)$ respectively. The regression analysis of corresponding AUCs verified a positive correlation between the ACTH and corticosterone response to CRH in TGR(ASrAOGEN) and controls (Fig. 1C). However, the regression line relating to TGR(ASrAOGEN) was shifted upwards (Fig. 1C) indicating an improved sensitivity towards ACTH. Accordingly, the mean

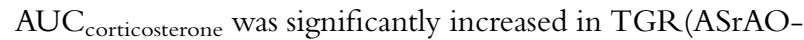
GEN) (34 535 \pm 3047 vs $22209 \pm 3911 \mathrm{pg} / \mathrm{ml}$ per min, $P=0.0202)$, whereas the mean $\mathrm{AUC}_{\mathrm{ACTH}}$ was similar between TGR(ASrAOGEN) and controls (Fig. 1C).

Table 2 Endocrine parameters of TGR(ASrAOGEN) rats and controls. Means \pm S.E.M. $(n=8-13)$

\begin{tabular}{|c|c|c|c|}
\hline & Control & TGR(ASrAOGEN) & $\boldsymbol{P}$ \\
\hline Plasma ACTH (pg/ml) & $110 \pm 15$ & $91 \pm 9$ & $\overline{0 \cdot 148}$ \\
\hline $\begin{array}{l}\text { Plasma corticosterone } \\
\qquad(\mathrm{ng} / \mathrm{ml})\end{array}$ & $152 \pm 34$ & $135 \pm 20$ & $0 \cdot 329$ \\
\hline $\begin{array}{l}\text { Plasma aldosterone } \\
(\mathrm{ng} / \mathrm{ml})\end{array}$ & $191 \pm 32$ & $1091 \pm 34$ & 0.096 \\
\hline $\begin{array}{l}\text { Plasma norepinephrine } \\
(\mathrm{pg} / \mathrm{ml})\end{array}$ & $1039 \pm 96$ & $844 \pm 96$ & $0 \cdot 164$ \\
\hline $\begin{array}{l}\text { Plasma epinephrine } \\
(\mathrm{pg} / \mathrm{ml})\end{array}$ & $654 \pm 95$ & $512 \pm 75$ & $0 \cdot 281$ \\
\hline
\end{tabular}



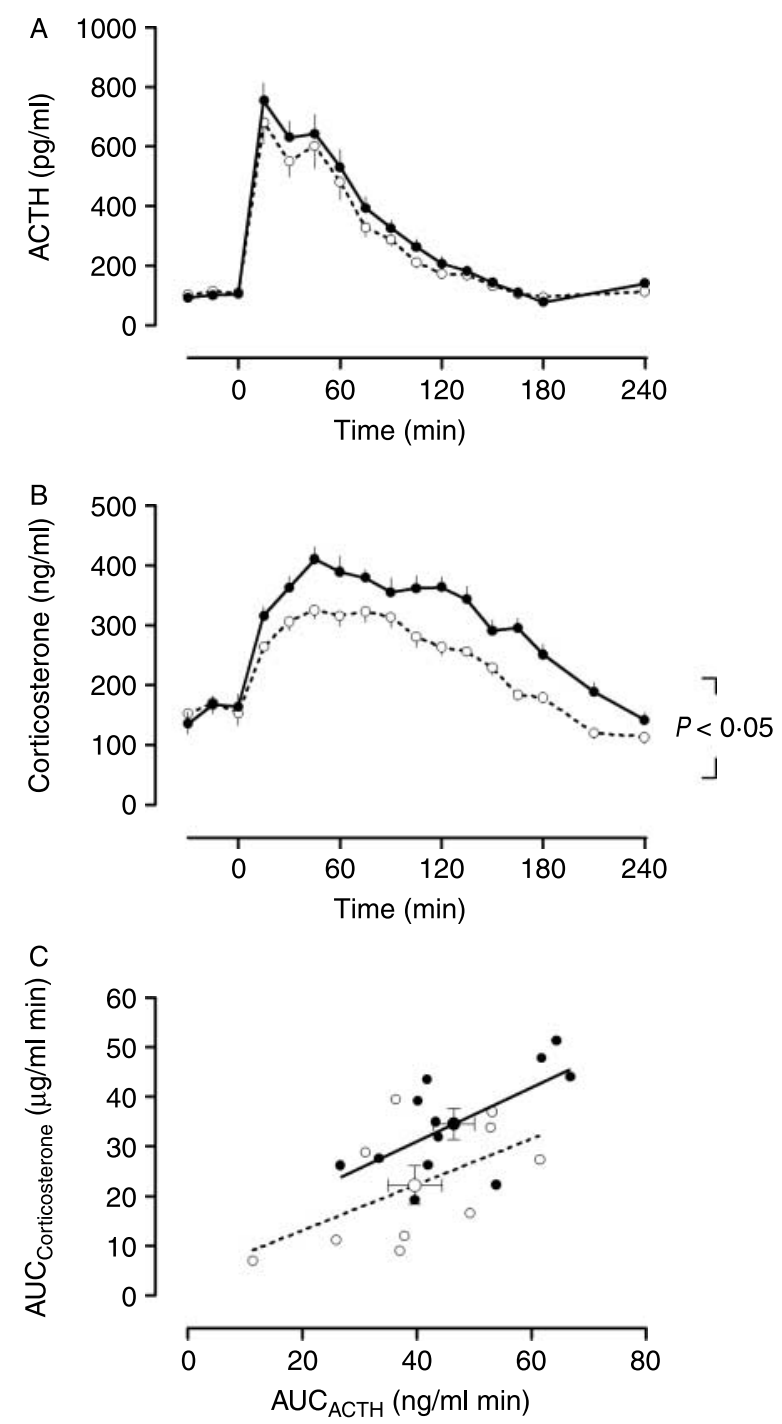

Figure 1 Plasma profiles of ACTH (A) and corticosterone (B) in response to $\mathrm{CRH}(10 \mu \mathrm{g} / \mathrm{kg}$ i.v.) in TGR(ASrAOGEN) (O) and controls $(\mathrm{O})$. The increase in corticosterone response was statistically evaluated by two-way ANOVA. (C) Correlation between $\mathrm{CRH}$-induced alterations of cumulative plasma concentrations of $\mathrm{ACTH}$ and corticosterone (depicted as AUC of the corresponding concentration-time curves; see Fig. 1) in TGR(ASrAOGEN) ( solid line, Pearson $R=0 \cdot 6447, P=0 \cdot 0118$ ) and controls $(O$, dotted line, Pearson $R=0.5572, P=0 \cdot 0471)$. Means \pm s.E.M. $(n=10-12)$.

After FST, the plasma levels of ACTH and corticosterone increased in TGR(ASrAOGEN) and controls to a similar extent compared to the CRH test (Fig. 2A and B). The corticosterone response was enlarged in TGR(ASrAOGEN), which was not again associated with a concurrent increase in ACTH. This was emphasized by the graphical analysis of the correlations between ACTH and corticosterone values. Consistently with the $\mathrm{CRH}$ test, the regression line representing the TGR(ASrAOGEN) was shifted upwards (Fig. 2C).
In order to determine the impact of the adrenals on the sensitization of the HPA axis in TGR(ASrAOGEN), an ACTH test was performed. Baseline corticosterone levels did not differ between both rat strains $(129 \pm 5$ vs 100 $\pm 14 \mathrm{ng} / \mathrm{ml} ; P=0 \cdot 088)$. In response to ACTH, increase in corticosterone was slightly heightened in TGR(ASrAOGEN) compared to controls (Fig. 3).
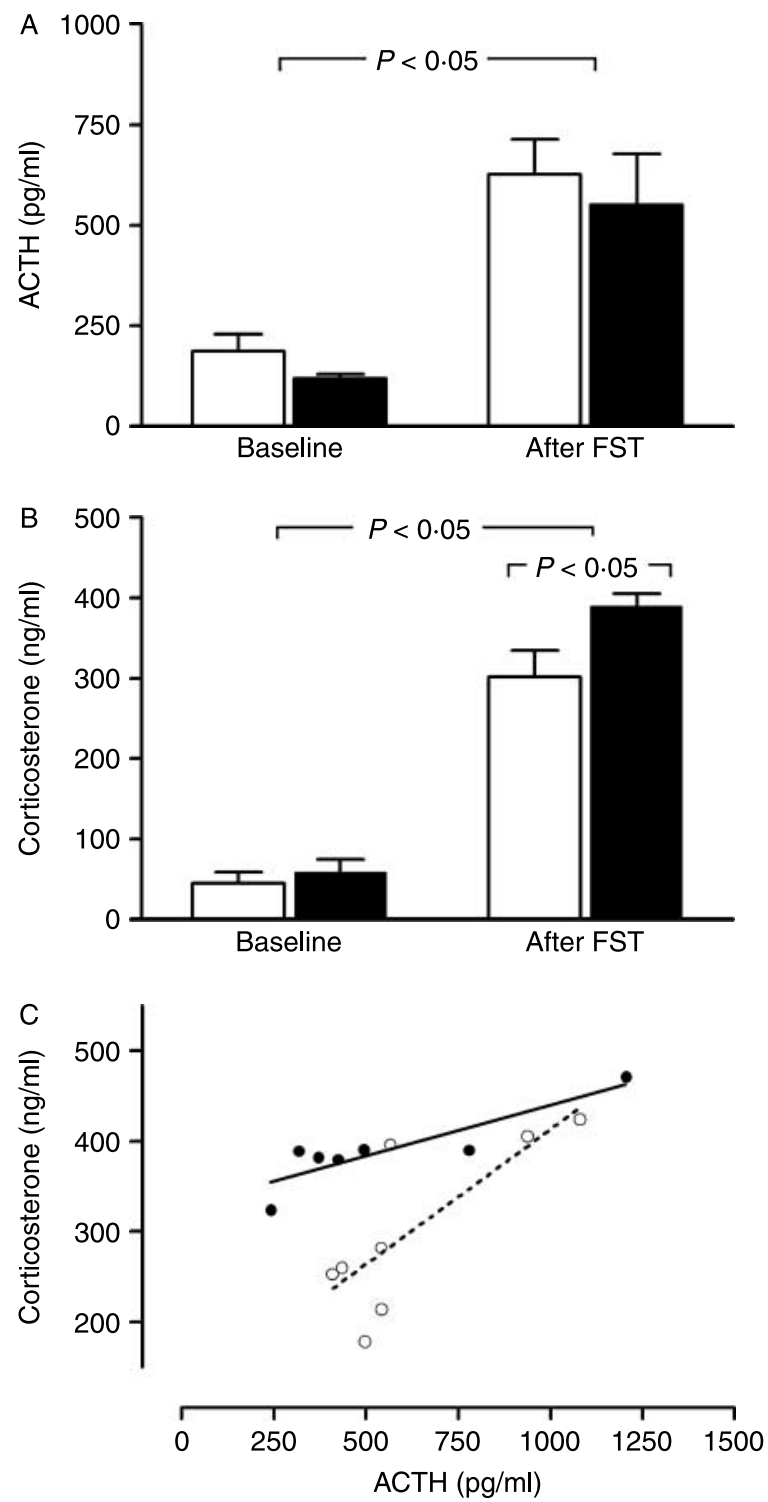

Figure 2 Plasma concentrations of $\mathrm{ACTH}(\mathrm{A})$ and corticosterone (B) before and after TGR(ASrAOGEN) (closed bars) and controls (open bars) were stressed by a forced swim test (FST, $10 \mathrm{~min} 15^{\circ} \mathrm{C}$ ).

The stress response and the increase in corticosterone after FST were statistically evaluated by two-way ANOVA. In (C), the correlation between ACTH and corticosterone after FST in TGR(ASrAOGEN)

$(\bullet$, solid line, Pearson $R=0 \cdot 8771, P=0 \cdot 0048)$ and controls ( $O$, dotted line, Pearson $R=0.7777, P=0.0115$ ) is depicted. Means \pm S.E.M. $(n=7-8)$. 
The steady-state mRNA levels of Crh and Pome in the hypothalami and pituitary glands were similar between both strains (Fig. 4). The steady-state mRNA levels of MC2 receptors were increased by one-third in the adrenals of TGR(ASrAOGEN) (Fig. 5). Finally, while the mRNA levels of $\mathrm{AT}_{1 \mathrm{~A}}$ and $\mathrm{AT}_{1 \mathrm{~B}}$ receptors in the organs of the HPA axis did not differ between the two rat strains (Tables 3 and 4), the adrenal mRNA levels of $\mathrm{AT}_{2}$ receptors were doubled in TGR(ASrAOGEN) (Fig. 5).

\section{Discussion}

Recently, we have shown that inhibition of $\mathrm{AT}_{1}$ receptors attenuates HPA axis reactivity. A reduced pituitary sensitivity to $\mathrm{CRH}$ and a downregulation of hypothalamic $\mathrm{CRH}$ expression were speculated to underlie these effects (Raasch et al. 2006). Following on from this, in this study, we aimed to confirm the relevancy of Ang II-dependent central mechanisms for regulating HPA activity by using TGR(ASrAOGEN) that lacked brain Ang II (Schinke et al. 1999). Consistent with many other studies, a slight hypotension was observed in the TGR(ASrAOGEN), which served as the fundamental characteristic of this transgenic rat in most of the studies (Baltatu et al. 2000, 2001, Wang et al. 2004, Campos et al. 2006).

At first sight, TGR(ASrAOGEN) and controls do not seem to differ regarding stress parameters, since baseline levels of ACTH, corticosterone, aldosterone, norepinephrine, epinephrine, and adrenal weights were all similar. Even though morphometric examinations were not carried out, we speculate here that zonal differentiation was not altered in the adrenal cortex of TGR(ASrAOGEN), since no changes or hypertrophy in response to Ang II were observed in the zona fasciculata or the zona glomerulosa (Ogishima et al. 1992, McEwan et al. 1999, Aguilar et al. 2004). In accordance with these findings, baseline levels of stress hormones also remained unaffected in SHR after chronic $\mathrm{AT}_{1}$ blockade

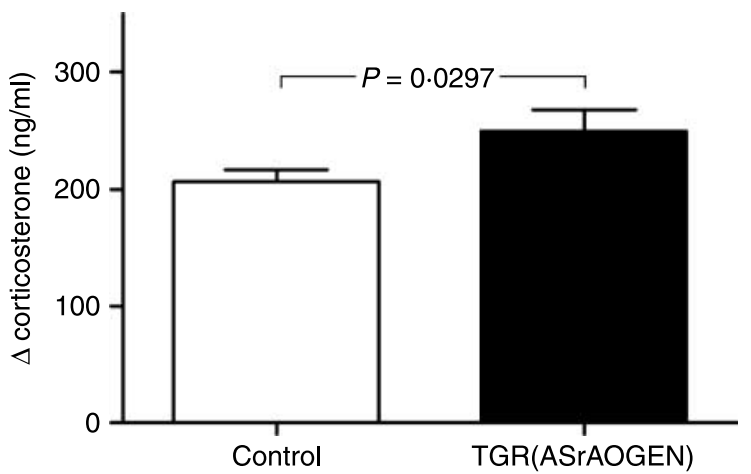

Figure 3 Maximal increase of corticosterone in response to ACTH $(2 \mu \mathrm{g} / \mathrm{kg}$ i.v. $)$ in TGR(ASrAOGEN) and controls; means \pm s.E.M. $(n=7-8)$. Significance of corticosterone response to ACTH was calculated by Student's $t$-test.
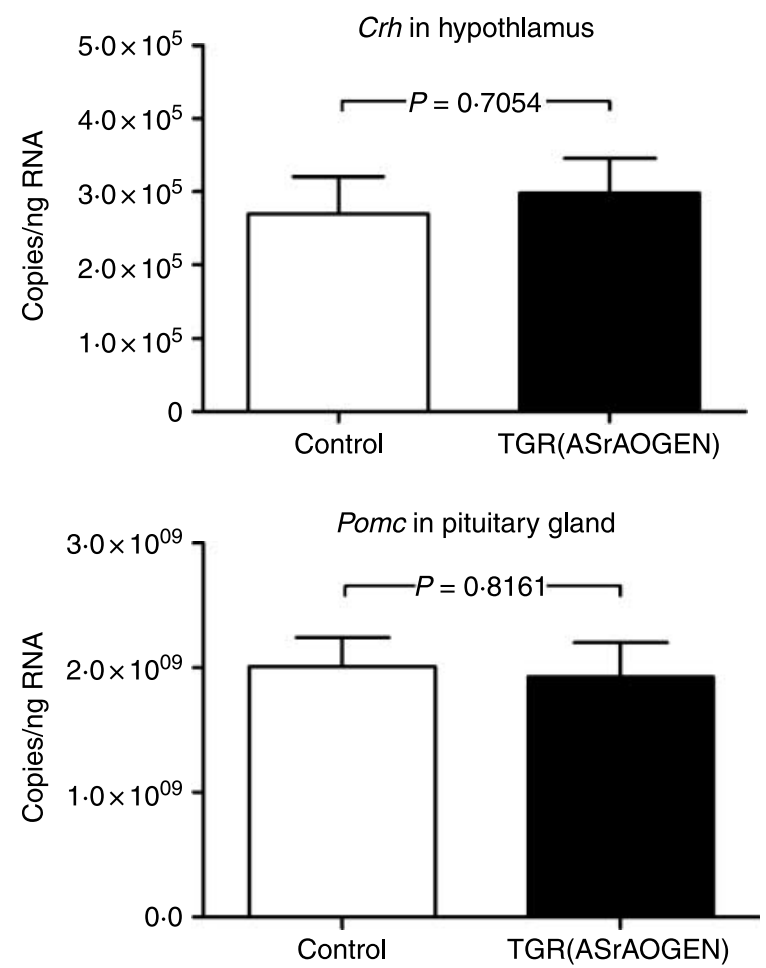

Figure 4 Steady-state mRNA levels of $\mathrm{Crh}$ (in the hypothalamus) and Pomc (in the pituitary gland) of TGR(ASrAOGEN) and controls. Means \pm S.E.M. $(n=7-10)$.

(Raasch et al. 2006). In contrast to our expectations and the observation that HPA reactivity is increased by Ang II and reduced by $\mathrm{AT}_{1}$ blockade (Raasch et al. 2006, Müller et al. 2007), the CRH-induced corticosterone response in TGR(ASrAOGEN) was by no means diminished, but in fact increased. In order to confirm our results, a second stress test was performed. Accordant to the $\mathrm{CRH}$ challenge, the corticosterone plasma levels raised to the same extent after FST, and the stress-induced increase in corticosterone was enlarged in TGR(ASrAOGEN). The stimulated corticosterone response in TGR(ASrAOGEN) was not associated with a concurrent increase in ACTH in the CRH test or FST. As such, a combined hypothalamic and pituitary related mechanism seems rather unlikely. This conclusion is further supported by similar Crh and Pomc mRNA levels in the hypothalamus and pituitary glands of TGR(ASrAOGEN). However, i.c.v. or peripheral administrations of $\mathrm{AT}_{1}$ blockers were found to alleviate the increases in hypothalamic $\mathrm{Crh}$ mRNA or pituitary ACTH in response to stress (Jezova et al. 1998, Raasch et al. 2006). While this inhibiting effect was observed in animals that were exposed to stress (Jezova et al. 1998, Raasch et al. 2006), the Crh and Pomc mRNA levels presented here reflect native expression in the organs of rats, thus accounting for the differences between our and the cited studies. 

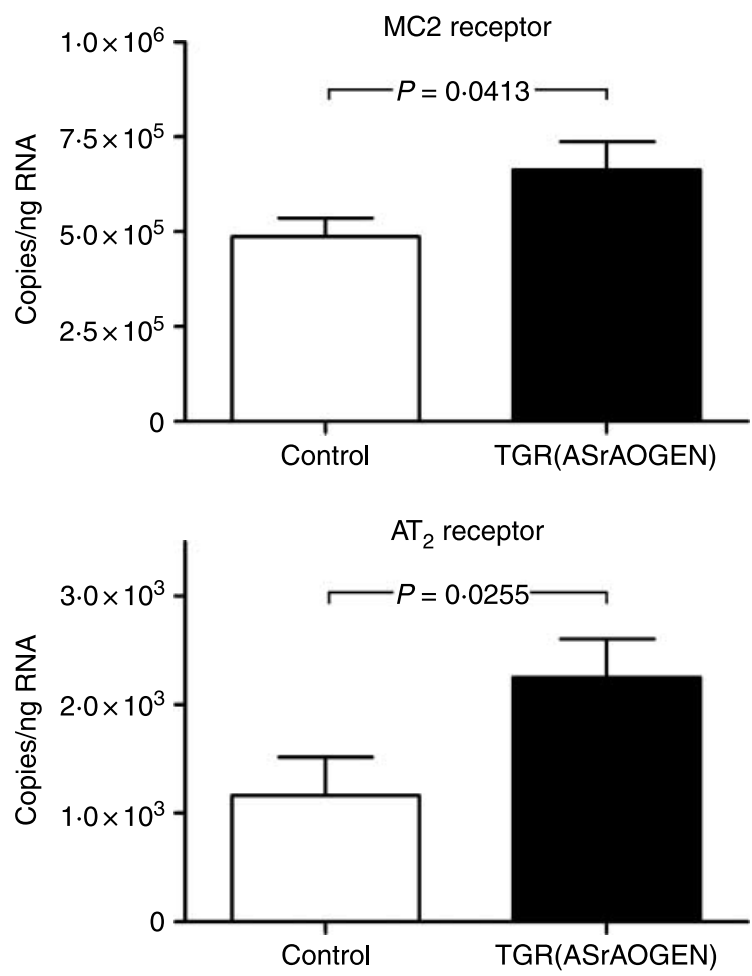

Figure 5 Steady-state mRNA levels of the MC2 receptor and the $\mathrm{AT}_{2}$ receptor in the adrenal glands of TGR(ASrAOGEN) and controls. Means \pm s.E.M. $(n=7-10)$. Quantitative mutual information score (MC2 receptor) and Student's $t$-test $\left(\mathrm{AT}_{2}\right.$ receptor) were performed to prove statistical significance.

The ACTH independency of simulated corticosterone responses to stress indicates an adrenal mechanism. We asked whether the adrenal MC2 receptor expression is increased, since this subtype of $\mathrm{MC}$ receptor preferentially promotes the ACTH-induced corticosterone response (Chhajlani et al. 1993, Liakos et al. 1998). In human adrenal fasciculata cells, Ang II and ACTH stimulated the expression of the MC2 receptor (Lebrethon et al. 1994, Penhoat et al. 1994, 1995, Naville et al. 2001, Blondet et al. 2002). In bovine adrenal fasciculata cells, Ang II was hypothesized to induce a steroidogenic desensitization (Penhoat et al. 1995), justifying our speculation that the MC2 receptor is increased in TGR(ASrAOGEN). Indeed, steady-state levels of MC2 receptor mRNA were increased in TGR(ASrAOGEN). It therefore seems conceivable that an upregulation of the

Table 3 Steady-state levels of $m R N A$ of $\mathrm{AT}_{1 \mathrm{~A}}$ receptors in organs of the hypothalamo-pituitary-adrenal axis of TGR(ASrAOGEN) and controls. Means \pm S.E.M. $(n=7-10)$

\begin{tabular}{|c|c|c|c|}
\hline & Control & TGR(ASrAOGEN) & $\boldsymbol{P}$ \\
\hline Hypothalami & $4 \cdot 7 \pm 0 \cdot 6 \times 10^{5}$ & $5 \cdot 3 \pm 0 \cdot 7 \times 10^{5}$ & $0 \cdot 547$ \\
\hline Pituitary glands & $8 \cdot 1 \pm 0.6 \times 10^{5}$ & $7 \cdot 3 \pm 0.6 \times 10^{5}$ & $0 \cdot 431$ \\
\hline Adrenal glands & $5 \cdot 6 \pm 0.6 \times 10^{5}$ & $7 \cdot 3 \pm 0.9 \times 10^{5}$ & $0 \cdot 066$ \\
\hline
\end{tabular}

Table 4 Steady-state levels of mRNA of $\mathrm{AT}_{1 \mathrm{~B}}$ receptors in organs of the hypothalamo-pituitary-adrenal axis of TGR(ASrAOGEN) and controls. Means \pm S.E.M. $(n=7-10)$

\begin{tabular}{|c|c|c|c|}
\hline & Control & TGR(ASrAOGEN) & $\boldsymbol{P}$ \\
\hline 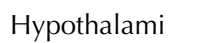 & $4 \cdot 2 \pm 0 \cdot 5 \times 10^{4}$ & $6 \cdot 2 \pm 0.9 \times 10^{4}$ & $0 \cdot 068$ \\
\hline Pituitary glands & $6 \cdot 9 \pm 1.0 \times 104$ & $6 \cdot 1 \pm 0.7 \times 10^{4}$ & 0.532 \\
\hline Adrenal glands & $4.5 \pm 0.7 \times 10^{4}$ & $5 \cdot 5 \pm 0.8 \times 10^{4}$ & $0 \cdot 366$ \\
\hline
\end{tabular}

MC2 receptor may account for the stimulated corticosterone response to stress in TGR(ASrAOGEN). In order to confirm this mechanism functionally, the adrenal responsiveness to ACTH was investigated. In accordance with our hypothesis, plasma corticosterone in response to ACTH was slightly enhanced in TGR(ASrAOGEN) compared to controls.

Whether other mechanisms besides the upregulation of MC2 receptor may be involved in the increased stress response in TGR(ASrAOGEN) is discussed in the following:

Ang II stimulates glucocorticoid release by enhancing the CRH-mediated ACTH release (Gaillard et al. 1981, 1985, Abou-Samra et al. 1986, Schoenenberg et al. 1987) or by stimulating adrenal glucocorticoid production (Naville et al. 1993). We recently demonstrated that Ang II increased the corticosterone responsiveness to $\mathrm{CRH}$, an effect that was associated with an upregulation of the $\mathrm{AT}_{1 \mathrm{~A}}$ receptor (Müller et al. 2007). This poses the question whether $\mathrm{AT}_{1}$ receptors are enhanced in the organs of the HPA axis of the TGR(ASrAOGEN), and whether this causes the observed stress sensitization. We found no alterations in the mRNA levels of the $\mathrm{AT}_{1}$ receptor, indicating that the hypersensitization to stress is minor compared to alterations in the $\mathrm{AT}_{1}$ receptor. A limitation of our study was that we determined mRNA levels rather than protein or $\mathrm{AT}_{1}$ binding, even considering that $\mathrm{AT}_{1}$ receptor binding was significantly higher inside various regions of the blood-brain barrier of TGR(ASrAOGEN) compared to controls (Monti et al. 2001). While hypothalamic $\mathrm{AT}_{1}$ receptors are less stimulated in TGR(ASrAOGEN) by locally generated Ang II, it should be questioned whether peripherally generated Ang II causes the enhanced stress response. The following points tend to argue against an impact of peripherally arising Ang II: 1) if circulating Ang II is really involved in stress sensitization via hypothalamic $\mathrm{AT}_{1}$ receptors, the ACTH response should also be enhanced; however, in our study, the potentiation of corticosterone response occurred ACTH independently; 2) even considering that glucocorticoids are potent activators of angiotensinogen gene expression (Brasier \& Li 1996), Ang II does not penetrate the blood-brain barrier (Schelling et al. 1976) and 3) Ang II may indeed act upon $\mathrm{AT}_{1}$ receptors in the circumventricular organs, but $\mathrm{AT}_{1}$ receptor binding was clearly shown to be decreased in these areas (Monti et al. 2001). It is certainly true that the increase in $\mathrm{AT}_{2}$ receptor mRNA in the adrenals of TGR(ASrAOGEN) may also have been related to the stimulated stress response of the transgenic rats, since another study on bovine fasciculata cells showed 
that cortisol production was stimulated through $\mathrm{AT}_{2}$ receptors, and thus independently of an $\mathrm{AT}_{1}$-mediated mechanism (Defaye et al. 1995).

$\mathrm{CRH}$ is a key hormone in the integrated response to stress, which stimulates sympathetic outflow in addition to regulating pituitary ACTH release. Sympathoexcitatory responses to air-jet stress were found to be similar between TGR(ASrAOGEN) and controls, and between Wistar rats receiving i.c.v. infusions of losartan or vehicle (Zhang et al. 1999, Wang et al. 2004). This indicates that the brain RAAS appears to play only a small role in the control of sympathetic function during stress. Our findings that hypothalamic Crh expression as well as baseline epinephrine did not differ between controls and TGR(ASrAOGEN) may strengthen this idea, even though we are aware that we have not determined changes during stress reactions. Peripheral RAAS certainly does influence sympathoexcitatory responses to stress, since adrenal biosynthesis and secretion of catecholamines are reduced after $\mathrm{AT}_{1}$ blockade (Armando et al. 2001).

\section{Declaration of interest}

The authors declare that there is no conflict of interest that could be perceived as prejudicing the impartiality of the research reported.

\section{Funding}

This study was supported by a grant (N11-2004) held by the Dean of the Medical Faculty of the University of Lübeck.

\section{Acknowledgements}

The authors would like to thank Mrs A Kaiser for expert technical assistance, and Dr J P Keogh for assisting in the editing of the manuscript.

\section{References}

Abou-Samra AB, Catt KJ \& Aguilera G 1986 Involvement of protein kinase C in the regulation of adrenocorticotropin release from rat anterior pituitary cells. Endocrinology 118 212-217.

Aguilar F, Lo M, Claustrat B, Saez JM, Sassard J \& Li JY 2004 Hypersensitivity of the adrenal cortex to trophic and secretory effects of angiotensin II in Lyon genetically-hypertensive rats. Hypertension 43 87-93.

Aguilera G, Kiss A \& Luo X 1995 Increased expression of type 1 angiotensin II receptors in the hypothalamic paraventricular nucleus following stress and glucocorticoid administration. Journal of Neuroendocrinology 7 775-783.

Armando I, Carranza A, Nishimura Y, Hoe KL, Barontini M, Terron JA, Falcon-Neri A, Ito T, Juorio AV \& Saavedra JM 2001 Peripheral administration of an angiotensin II AT(1) receptor antagonist decreases the hypothalamic-pituitary-adrenal response to isolation stress. Endocrinology 142 3880-3889.

Baltatu O, Silva JA Jr, Ganten D \& Bader M 2000 The brain renin-angiotensin system modulates angiotensin II-induced hypertension and cardiac hypertrophy. Hypertension 35 409-412.

Baltatu O, Janssen BJ, Bricca G, Plehm R, Monti J, Ganten D \& Bader M 2001 Alterations in blood pressure and heart rate variability in transgenic rats with low brain angiotensinogen. Hypertension 37 408-413.
Blondet A, Doghman M, Penhoat A, Durand P, Begeot M \& Naville D 2002 The human MC2-R gene expression: different aspects of its control. Endocrine Research 28 275-280.

Brasier AR \& Li J 1996 Mechanisms for inducible control of angiotensinogen gene transcription. Hypertension 27 465-475.

Burson JM, Aguilera G, Gross KW \& Sigmund CD 1994 Differential expression of angiotensin receptor $1 \mathrm{~A}$ and $1 \mathrm{~B}$ in mouse. American Journal of Physiology 267 E260-E267.

Bustin SA 2002 Quantification of mRNA using real-time reverse transcription PCR (RT-PCR): trends and problems. Journal of Molecular Endocrinology 29 23-39.

Camara AK \& Osborn JL $1998 \mathrm{AT}_{1}$ receptors mediate chronic central nervous system AII hypertension in rats fed high sodium chloride diet from weaning. Journal of the Autonomic Nervous System 72 16-23.

Campos LA, Plehm R, Cipolla-Neto J, Bader M \& Baltatu OC 2006 Altered circadian rhythm reentrainment to light phase shifts in rats with low levels of brain angiotensinogen. American Journal of Physiology. Regulatory, Integrative and Comparative Physiology 290 R1122-R1127.

Castren E \& Saavedra JM 1988 Repeated stress increases the density of angiotensin II binding sites in rat paraventricular nucleus and subfornical organ. Endocrinology 122 370-372.

Chan O, Inouye K, Vranic M \& Matthews SG 2002 Hyperactivation of the hypothalamo-pituitary-adrenocortical axis in streptozotocin-diabetes is associated with reduced stress responsiveness and decreased pituitary and adrenal sensitivity. Endocrinology 143 1761-1768.

Chan O, Inouye K, Riddell MC, Vranic M \& Matthews SG 2003 Diabetes and the hypothalamo-pituitary-adrenal (HPA) axis. Minerva Endocrinologica 28 87-102.

Chhajlani V, Muceniece R \& Wikberg JE 1993 Molecular cloning of a novel human melanocortin receptor. Biochemical and Biophysical Research Communications 195 866-873.

Defaye G, Lecomte S, Chambaz EM \& Bottari SP 1995 Stimulation of cortisol production through angiotensin $\mathrm{AT}_{2}$ receptors in bovine fasciculata cells. Endocrine Research 21 183-187.

Djavidani B, Sander M, Kreutz R, Zeh K, Bader M, Mellon SH, Vecsei P, Peters J \& Ganten D 1995 Chronic dexamethasone treatment suppresses hypertension development in the transgenic rat TGR(mREN2)27. Journal of Hypertension 13 637-645.

Gaillard RC, Grossman A, Gillies G, Rees LH \& Besser GM 1981 Angiotensin II stimulates the release of ACTH from dispersed rat anterior pituitary cells. Clinical Endocrinology 15 573-578.

Gaillard RC, Favrod-Coune CA, Capponi AM \& Muller AF 1985 Corticotropin-releasing activity of the renin-angiotensin system peptides in rat and in man. Neuroendocrinology 41 511-517.

Gasc JM, Shanmugam S, Sibony M \& Corvol P 1994 Tissue-specific expression of type 1 angiotensin II receptor subtypes. An in situ hybridization study. Hypertension 24 531-537.

Jezova D, Ochedalski T, Kiss A \& Aguilera G 1998 Brain angiotensin II modulates sympathoadrenal and hypothalamic pituitary adrenocortical activation during stress. Journal of Neuroendocrinology 10 67-72.

Jöhren O \& Saavedra JM 1996 Expression of $\mathrm{AT}_{1 \mathrm{~A}}$ and $\mathrm{AT}_{1 \mathrm{~B}}$ angiotensin II receptor messenger RNA in forebrain of 2-wk-old rats. American Journal of Physiology 271 E104-E112.

Jöhren O, Inagami T \& Saavedra JM $1995 \mathrm{AT}_{1 \mathrm{~A}}, \mathrm{AT}_{1 \mathrm{~B}}$, and $\mathrm{AT}_{2}$ angiotensin II receptor subtype gene expression in rat brain. Neuroreport 6 2549-2552.

Jöhren O, Neidert SJ, Kummer M, Dendorfer A \& Dominiak P 2001 Prepro-orexin and orexin receptor $\mathrm{mRNAs}$ are differentially expressed in peripheral tissues of male and female rats. Endocrinology 142 3324-3331.

Jöhren O, Golsch C, Dendorfer A, Qadri F, Häuser W \& Dominiak P 2003 Differential expression of $\mathrm{AT}_{1}$ receptors in the pituitary and adrenal gland of SHR and WKY. Hypertension 41 984-990.

Jöhren O, Dendorfer A, Dominiak P \& Raasch W 2007 Gene expression of mineralocorticoid and glucocorticoid receptors in the limbic system is related to type-2 like diabetes in leptin-resistant rats. Brain Research 1184 160-167. 
Lebrethon MC, Naville D, Begeot M \& Saez JM 1994 Regulation of corticotropin receptor number and messenger RNA in cultured human adrenocortical cells by corticotropin and angiotensin II. Journal of Clinical Investigation 93 1828-1833.

Leong DS, Terron JA, Falcon-Neri A, Armando I, Ito T, Jöhren O, Tonelli LH, Hoe KL \& Saavedra JM 2002 Restraint stress modulates brain, pituitary and adrenal expression of angiotensin II AT(1A), AT(1B) and AT(2) receptors. Neuroendocrinology $\mathbf{7 5} 227-240$.

Liakos P, Chambaz EM, Feige JJ \& Defaye G 1998 Expression of ACTH receptors (MC2-R and MC5-R) in the glomerulosa and the fasciculatareticularis zones of bovine adrenal cortex. Endocrine Research 24 427-432.

Llorens-Cortes C, Greenberg B, Huang H \& Corvol P 1994 Tissular expression and regulation of type 1 angiotensin II receptor subtypes by quantitative reverse transcriptase-polymerase chain reaction analysis. Hypertension 24 538-548.

McEwan PE, Vinson GP \& Kenyon CJ 1999 Control of adrenal cell proliferation by $\mathrm{AT}_{1}$ receptors in response to angiotensin II and low-sodium diet. American Journal of Physiology 276 E303-E309.

Monti J, Schinke M, Bohm M, Ganten D, Bader M \& Bricca G 2001 Glial angiotensinogen regulates brain angiotensin II receptors in transgenic rats TGR(ASrAOGEN). American Journal of Physiology. Regulatory, Integrative and Comparative Physiology 280 R233-R240.

Müller H, Schweitzer N, Jöhren O, Dominiak P \& Raasch W 2007 Angiotensin II stimulates the reactivity of the pituitary-adrenal-axis in leptin resistant Zucker rats thereby influencing the glucose utilization. American Journal of Physiology. Endocrinology and Metabolism 293 E802-E810.

Naville D, Lebrethon MC, Kermabon AY, Rouer E, Benarous R \& Saez JM 1993 Characterization and regulation of the angiotensin II type-1 receptor (binding and mRNA) in human adrenal fasciculata-reticularis cells. FEBS Letters 321 184-188.

Naville D, Bordet E, Berthelon MC, Durand P \& Begeot M 2001 Activator protein-1 is necessary for angiotensin-II stimulation of human adrenocorticotropin receptor gene transcription. European Journal of Biochemistry 268 1802-1810.

Ogishima T, Suzuki H, Hata J, Mitani F \& Ishimura Y 1992 Zone-specific expression of aldosterone synthase cytochrome P-450 and cytochrome P-45011 beta in rat adrenal cortex: histochemical basis for the functional zonation. Endocrinology 130 2971-2977.

Oliveira DR, Santos RA, Santos GF, Khosla M \& Campagnole-Santos MJ 1996 Changes in the baroreflex control of heart rate produced by central infusion of selective angiotensin antagonists in hypertensive rats. Hypertension 27 1284-1290.

Paxinos G \& Watson C 1998 The Rat Brain in Stereotaxic Coordinates. San Diego: Academic Press.

Penhoat A, Jaillard C \& Saez JM 1994 Regulation of bovine adrenal cell corticotropin receptor mRNA levels by corticotropin (ACTH) and angiotensin-II (A-II). Molecular and Cellular Endocrinology 103 R7-10.

Penhoat A, Lebrethon MC, Begeot M \& Saez JM 1995 Regulation of ACTH receptor mRNA and binding sites by ACTH and angiotensin II in cultured human and bovine adrenal fasciculata cells. Endocrine Research 21 157-168.

Raasch W, Dominiak P, Ziegler A \& Dendorfer A 2004a Reduction of vascular noradrenaline sensitivity by $\mathrm{AT}_{1}$ antagonists depends on functional sympathetic innervation. Hypertension 44 346-351.
Raasch W, Jöhren O, Schwartz S, Gieselberg A \& Dominiak P $2004 b$ Combined blockade of $\mathrm{AT}_{1}$-receptors and $\mathrm{ACE}$ synergistically potentiates antihypertensive effects in SHR. Journal of Hypertension 22 611-618.

Raasch W, Dominiak P \& Dendorfer A 2005 Angiotensin I-converting enzyme-dependent and neutral endopeptidase-dependent generation and degradation of angiotensin II contrarily modulate noradrenaline release: implications for vasopeptidase-inhibitor therapy? Journal of Hypertension $\mathbf{2 3}$ 1597-1604.

Raasch W, Wittmershaus C, Dendorfer A, Voges I, Pahlke F, Dodt C, Dominiak P \& Jöhren O 2006 Angiotensin II inhibition reduces stress sensitivity of hypothalamo-pituitary-adrenal axis in SHR. Endocrinology 147 3539-3546.

Rivier C \& Vale W 1983 Effect of angiotensin II on ACTH release in vivo: role of corticotropin-releasing factor. Regulatory Peptides 7 253-258.

Sander M, Bader M, Djavidani B, Maser-Gluth C, Vecsei P, Mullins J, Ganten D \& Peters J 1992 The role of the adrenal gland in hypertensive transgenic rat TGR(mREN2)27. Endocrinology 131 807-814.

Schelling P, Hutchinson JS, Ganten U, Sponer G \& Ganten D 1976 Impermeability of the blood-cerebrospinal fluid barrier for angiotensin II in rats. Clinical Science \& Molecular Medicine 3 399s-402s.

Schinke M, Baltatu O, Bohm M, Peters J, Rascher W, Bricca G, Lippoldt A, Ganten D \& Bader M 1999 Blood pressure reduction and diabetes insipidus in transgenic rats deficient in brain angiotensinogen. PNAS 96 3975-3980.

Schoenenberg P, Kehrer P, Muller AF \& Gaillard RC 1987 Angiotensin II potentiates corticotropin-releasing activity of CRF41 in rat anterior pituitary cells: mechanism of action. Neuroendocrinology 45 86-90.

Seltzer A, Bregonzio C, Armando I, Baiardi G \& Saavedra JM 2004 Oral administration of an $\mathrm{AT}_{1}$ receptor antagonist prevents the central effects of angiotensin II in spontaneously hypertensive rats. Brain Research 1028 9-18.

Sumitomo T, Suda T, Nakano Y, Tozawa F, Yamada M \& Demura H 1991 Angiotensin II increases the corticotropin-releasing factor messenger ribonucleic acid level in the rat hypothalamus. Endocrinology $\mathbf{1 2 8}$ 2248-2252.

Tsalenko A, Sharan R, Kristensen V, Edvardsen H, Borresen-Dale AL, Ben Dor A \& Yakhini Z 2006 Analysis of SNP-expression association matrices. Journal of Bioinformatics and Computational Biology 4 259-274.

Uresin Y, Erbas B \& Ozek M 2004 Losartan may prevent the elevation of plasma glucose levels induced by chronic stress. Polish Journal of Pharmacology 56 271-273.

Wang H, Huang BS, Ganten D \& Leenen FH 2004 Prevention of sympathetic and cardiac dysfunction after myocardial infarction in transgenic rats deficient in brain angiotensinogen. Circulation Research 94 843-849.

Zhang W, Huang BS \& Leenen FH 1999 Brain renin-angiotensin system and sympathetic hyperactivity in rats after myocardial infarction. American Journal of Physiology 276 H1608-H1615.

Received in final form 1 October 2009

Accepted 6 October 2009

Made available online as an Accepted Preprint

6 October 2009 